\title{
Relating glacier mass balance to meteorological data by using a seasonal sensitivity characteristic
}

\author{
J. Oerlemans, ${ }^{1}$ B. K. Reighert ${ }^{2}$ \\ ${ }^{1}$ Institute for Marine and Atmospheric Research, Utrecht University, Princetonplein 5, 3584 CC Utrecht, The Netherlands \\ ${ }^{2}$ Max-Planck-Institut für Meteorologie, Bundesstrasse 55, D-20146 Hamburg, Germany
}

\begin{abstract}
We propose to quantify the climate sensitivity of the mean specific balance $B$ of a glacier by a seasonal sensitivity characteristic (SSC). The SSC gives the dependence of $B$ on monthly anomalies in temperature and precipitation. It is calculated from a mass-balance model. We show and discuss examples for Franz-Josef Glacier (New Zealand), Nigardsbreen (Norway), Hintereisferner (Austria), Peyto Glacier (Canadian Rockies), Abramov Glacier (Kirghizstan) and White Glacier (Canadian Arctic). With regard to the climate sensitivity of $B$, the SSCs clearly show that summer temperature is the most important factor for glaciers in a dry climate. For glaciers in a wetter climate, spring and fall temperatures also make a significant contribution to the overall sensitivity. The $\mathrm{SSC}$ is a $2 \times 12$ matrix. Multiplying it with monthly perturbations of temperature and precipitation for a particular year yields an estimate of the balance for that year. We show that, with this technique, mass-balance series can be (re)constructed from long meteorological records or from output of atmospheric models.
\end{abstract}

\section{INTRODUGTION}

Within a global context, glacier fluctuations are of interest primarily for two reasons. Firstly, historic glacier fluctuations contain information on past climatic change that can be extracted with modelling techniques (e.g. Nye, 1965; Smith and Budd, 1981; Oerlemans, 1997). Recently developed glacier modelling techniques make it easier to correct for geometric effects and extract a climate record from a glacier length record, for instance. Secondly, there is the generally accepted idea that glacier melt plays a significant role in global sea-level rise (Meier, 1984; Dyurgerov and Meier, 1997; Zuo and Oerlemans, 1997).

There is therefore a need to relate glacier mass balance to meteorological data. These data can be long records of instrumental observations, interpolated data from initialization schemes in weather-forecast models or output from atmospheric general circulation models (GCMs).

Many studies have been carried out in which regression techniques have been used to relate mean observed specific balance and/or equilibrium-line altitude to meteorological quantities (e.g. Lliboutry, 1974; Hoinkes and Steinacker, 1975; Letréguilly, 1984; Günther and Widlewski, 1986; Greuell, 1992). In such studies the number and type of predictands from glacier to glacier, depending on what is thought to be suitable for the given climatic setting. This makes it difficult to compare such studies. In most studies summer temperature and winter precipitation are assumed or found to be the best predictors, but summer and winter are not defined in a uniform way, so studies on different glaciers are hard to intercompare. In the near future, output from GCMs will be used more and more to make projections of glacier behaviour around the world. This calls for a more structured description of the climate-mass-balance relation.

We propose to define and use for individual glaciers a seasonal sensitivity characteristic (SSC) that gives the dependence of the mean specific balance on monthly perturbations in temperature and precipitation. The SSC is a $2 \times 12$ matrix, and multiplying it with an appropriate record of 12 monthly temperatures values and 12 monthly precipitation values yields an estimate of the mean specific balance. The fact that not only instrumental records but also GCM output is normally available in the form of monthly mean values makes it much easier to reconstruct or project the specific balance. It also facilitates the comparison of the climate sensitivity of individual glaciers. However, even for the longest mass-balance records it is not possible to derive monthly sensitivities in a statistical way, because the number of predictands (24) would be too large. So a massbalance model is needed to compute the SSC.

In section 2 we define the $\mathrm{SSC}$ and show examples for a selection of glaciers in different climatic settings. In section 3 we discuss how the SSG can be used to reconstruct the mean specific balance from a series of monthly values of temperature and precipitation. In section 4 a comparison is made between balance records from a full energy-balance calculation and from the simpler technique.

\section{THE SSC}

The mean specific balance of a glacier is the specific balance over the entire glacier surface and is denoted by $B$. As unit we use $m$ w.e. (metres of water equivalent). For a particular year the annual value of the balance with respect to a reference balance is denoted by $\Delta B$ :

$$
\Delta B=B-B_{\text {ref }}
$$


The basic idea is that $\Delta B$ can be related to monthly mean precipitation $P_{k}$ and temperature $T_{k}$ according to

$$
\Delta B_{\mathrm{m}}=\sum_{k=1}^{12}\left[C_{T, k}\left(T_{k}-T_{\mathrm{ref}, k}\right)+C_{P, k}\left(P_{k} / P_{\mathrm{ref}, k}\right)\right]+H
$$

where

$$
\begin{aligned}
C_{T, k} & =\frac{\partial B}{\partial T_{k}} \\
C_{P, k} & =\frac{\partial B}{\partial\left(P_{k} / P_{\text {ref }, k}\right)} .
\end{aligned}
$$

The index $k$ refers to the month $(k=1, \ldots, 12) . T_{\text {ref, } k}$ is defined as the temperature associated with the reference balance (preferably zero), so $C_{T, k}$ has unit mw.e. $\mathrm{K}^{-1}$. The dependent variable in the definition of $C_{P, k}$ is monthly precipitation divided by the precipitation in the reference case, and $C_{P, k}$ has unit m w.e.

Equation (2) can be regarded as a linearization of a more general expansion. The term $H$ represents all non-linear terms. This includes not only higher-order terms associated with the expansion for a particular month, but also crossterms in which a perturbation in a certain month several years ago may affect the actual balance through feedbacks in the system (e.g. albedo feedback due to a large positive anomaly in snow accumulation some time ago). The importance of such longer-term effects will be discussed in section 4 .

The SSC consists of the 24 values for $C_{T, k}$ and $C_{P, k}$ which can be calculated with a mass-balance model. This can be a degree-day model or an energy-balance model, simple or complex. The only requirement is that the model computes the cumulative balance through the year. Here we use the model described in Oerlemans (1992), with some minor changes. This is a mass-balance model of intermediate complexity, in which the energy exchange between atmosphere and glacier surface is treated in some detail. However, the thermodynamic processes inside the glacier are not modelled explicitly. The energetics involved in refreezing is dealt with in a schematic way. In Oerlemans and Fortuin (1992) this model was applied successfully to 12 glaciers for which good mass-balance observations exist. On the basis of some recently performed experimental meteorological work on glaciers (e.g. Greuell and others, 1998) some of the parameterizations have been adjusted (unpublished), but this has only a marginal effect on the basic properties of the model.

The calculation of a SSC proceeds as follows. For a particular glacier, the observed balance profile is simulated as well as possible by adjusting the climatological input within its range of uncertainty. The mean observed balance over the time-span of measurements is normally not zero, and to provide a reference state in which $B=0$ the annual mean air temperature is adjusted (in practice within $\pm 2 \mathrm{~K}$ ). Then the $C_{T, k}$ and $C_{P, k}$ values are determined by running the model for monthly temperature perturbations $(+0.5$ and $-0.5 \mathrm{~K})$ and monthly precipitation perturbations $(+10 \%$ and $-10 \%)$.

SSCs for a selection of glaciers are shown in Figure 1. The sample ranges from a glacier in a very wet climate (Franz-Josef Glacier, New Zealand: annual precipitation $P_{\text {ann }} \sim 6 \mathrm{~m}$ ), through glaciers in a moderately wet climate (e.g. Hintereisferner, Austria: $P_{\text {ann }} \sim 1.5 \mathrm{~m}$ ), to glaciers in a very dry climate (White Glacier, Canadian Arctic: $P_{\text {ann }} \sim 0.25 \mathrm{~m}$ ). Massbalance observations are not available from Franz-Josef Glacier, and the mass-balance model was calibrated in conjunc-
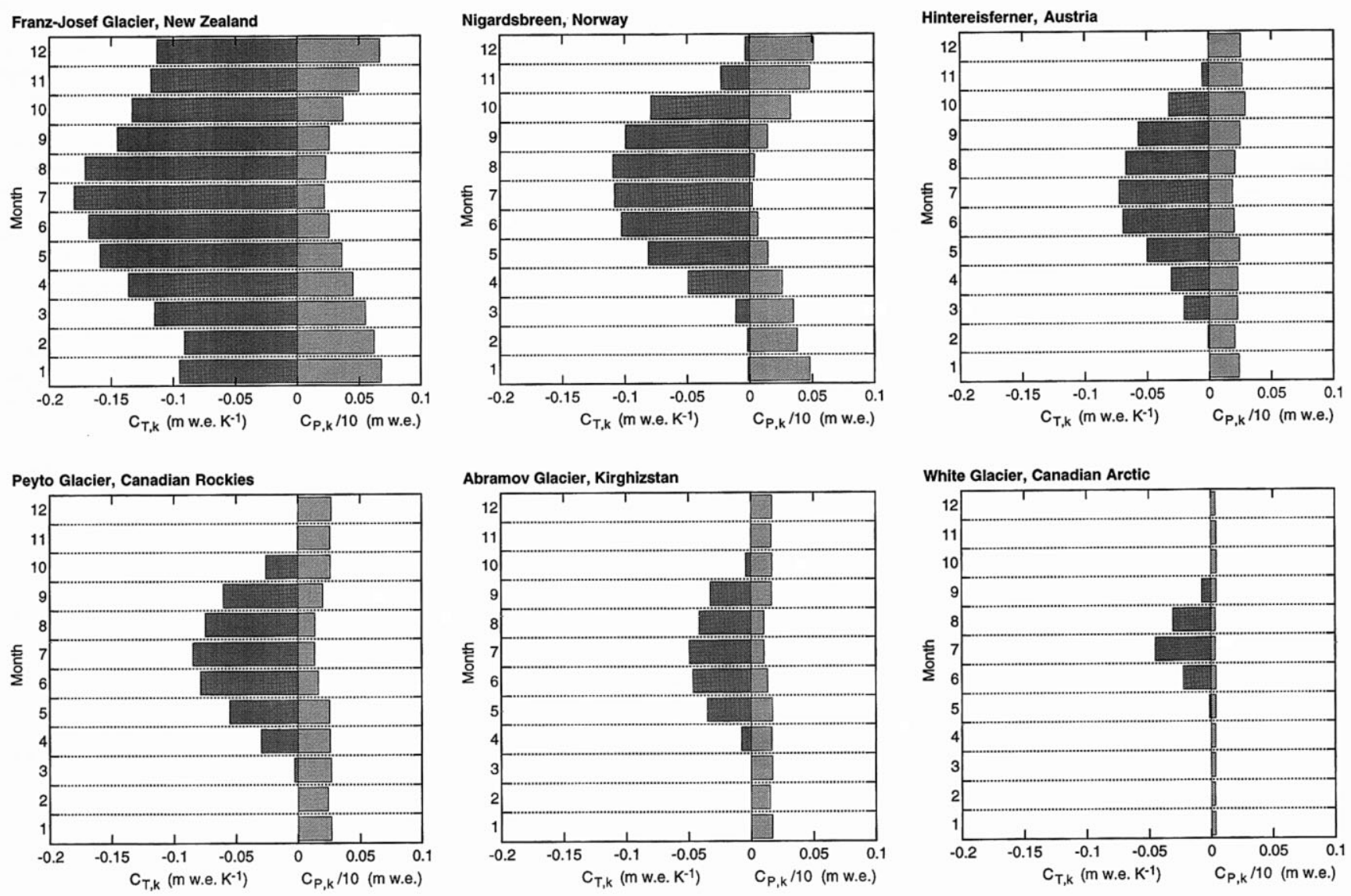

Fig. 1. Graphic representation of the SSC for a selection of glaciers, as calculated with a mass-balance model. To facilitate the comparison, the calendar for Franz-fosef Glacier, which is in the Southern Hemisphere, has been shifted over 6 months. 
tion with a study using a flowline model (Oerlemans, 1997). To allow a good comparison, all SSCs in Figure 1 have been plotted on the same scales.

From Figure 1 it is clear that the sensitivity of $B$ to temperature and precipitation changes increases dramatically with the amount of annual precipitation. This point was discussed by Oerlemans and Fortuin (1992) and confirms the long existing idea that glaciers with a large mass turnover are more sensitive (e.g. Meier, 1984).

When looking at the seasonal effects, a number of interesting observations can be made. For Nigardsbreen (Norway), winter precipitation is far more important than summer precipitation, as the latter falls as rain over most of the glacier. The maritime character of this glacier is also reflected in the temperature sensitivity. On the lower parts of the glacier the melt season is long, so May and September make a significant contribution. Franz-Josef Glacier (Southern Hemisphere) is even more maritime (note that the calendar has been shifted by half a year to make the graph comparable to those of the other glaciers). Even a temperature increase in the winter months leads to a reduced balance. This is because of higher melt rates on the tongue and because the fraction of precipitation falling as snow is significantly reduced. On the basis of this result, one would not attempt to seek a correlation between specific balance and summer temperature only.

Hintereisferner and Peyto Glacier (Canadian Rockies) are in a moderately wet climate. The accumulation areas of these glaciers cover a larger altitudinal range. As a result, an increase in summer precipitation still makes a significant contribution to the annual balance.

Abramov glacier (Kirghizstan) and White Glacier are both continental glaciers, but from very different latitudes (about $40^{\circ}$ and $79^{\circ} \mathrm{N}$, respectively). It appears that for drier glaciers the effect of temperature perturbations is more restricted to the summer. In fact, the temperature sensitivity for White Glacier is entirely determined by the summer months (June, July, August). For this glacier it matters little in what month an increase in precipitation takes place. Apparently, virtually all the precipitation falls as snow. It should be realized again that the seasonal variation of $C_{P, k}$ also depends on how the precipitation is distributed through the year. A more detailed analysis for Hintereisferner, for instance, shows that an equal increase in absolute precipitation through the year has the largest effect in early summer (due to increasing albedo in times of strong solar radiation). However, because the precipitation rate in early summer is lower than the annual mean, this effect does not show up in a sensitivity analysis based on fractional changes in precipitation.

In total the SSCs of 14 glaciers have been studied (in addition to the ones shown in Figure 1 these are: Engabreen, Ålfotbreen, Helstugubreen, Devon Ice Cap, Tuyuksu Glacier, Storglaciären, Rhonegletscher and Griesgletscher). Altogether, the most outstanding difference between the SSCs is in the length of the period for which temperature perturbations affect the annual balance. To quantify this, we introduce a seasonality index SI, defined as:

$$
\mathrm{SI}=\frac{C_{T, 6}+C_{T, 7}+C_{T, 8}}{\sum_{k=1}^{12}=C_{T, k}}
$$

In Figure 2 the SI values for the 14 glaciers are plotted against annual precipitation. A logarithmic fit is also shown, and the correlation coefficient is fairly large $(r=$

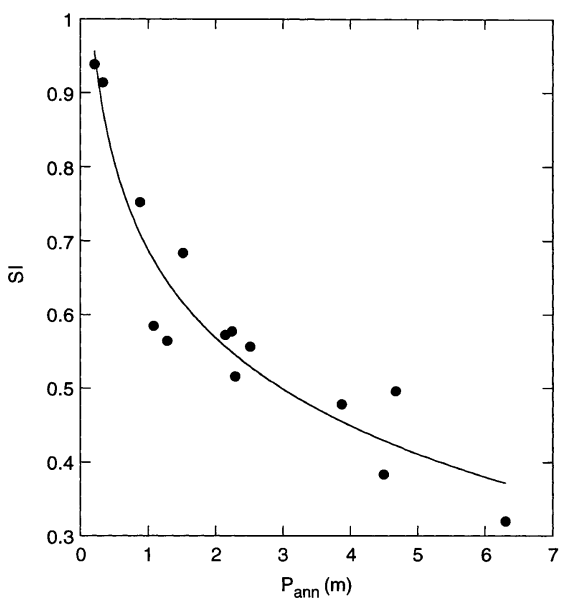

Fig. 2. The seasonality index (SI) plotted against annual precipitation $\left(P_{\mathrm{ann}}\right.$ ) for a sample of 14 glaciers (Franz-Fosef Glacier, Peyto Glacier, Nigardsbreen, Engabreen, Alfotbreen, Helstugubreen, Devon Ice Cap, White Glacier, Abramov Glacier, Tuyuksu Glacier, Storglaciären, Hintereisferner, Rhonegletscher and Griesgletscher).

0.955). Interestingly, the correlation coefficient of SI with the annual temperature range for the 14 glaciers is smaller $(r=0.82)$ but still significant. There is a relation between the annual temperature range and annual precipitation, of course: wetter climates generally have a smaller temperature range. As a general conclusion we state that the drier the climatic setting of a glacier, the more the sensitivity to temperature change is restricted to the summer months.

\section{APPLICATION OF THE SSG TO RECONSTRUCT A MASS-BALANCE SERIES}

To illustrate the use of the SSC, we have performed some calculations for Nigardsbreen. A series of annual balance perturbations $\Delta B(t)$, where $t$ is the year, was constructed from meteorological data with Equation (2) by omitting the term $H$. We refer to this model as the "reduced model" and formulate it as

$$
\Delta B(t)=\sum_{k=1}^{12}\left[\mathrm{SSC}_{1, k}\left(T_{k, t}-T_{\mathrm{ref}, k}\right)+\mathrm{SSC}_{2, k}\left(P_{k, t} / P_{\mathrm{ref}, k}\right)\right]
$$

Here the $\mathrm{SSC}$ is written as a $2 \times 12$ matrix $\mathrm{SSC}_{j, k}$, where the index $j$ refers to temperature $(j=1)$ or precipitation $(j=2)$ and the index $k$ to the number of the month. The temperature anomaly of month $k$ in year $t$ is denoted by $T_{k, t}$, the precipitation anomaly by $P_{k, t}$.

Three datasets were considered:

(i) A long series from the meteorological observatory at Bergen, western Norway. Precipitation and temperature data are available since 1921, and the station is a few hundred km away from Nigardsbreen.

(ii) Data from three weather stations, around the Jostedalsbreen plateau of which Nigardsbreen forms a part. These stations (Vangsnes, Fortun and Olde-Vangberg) are closer to Nigardsbreen, but the series are shorter. Monthly mean values for the three stations were used as input. The stations are located in deep valleys and therefore not necessarily more representative for the glacier area than Bergen. 
(iii) Data taken from the meteorological analysis of the European Centre for Medium-range Weather Forecasting (ECMWF), Reading, U.K., interpolated from gridpoints to the exact location of Nigardsbreen.

First we look at the results from the Bergen dataset (i), (see Fig. 3). In the first calculation, only the effect of temperature anomalies was considered $\left(\mathrm{SSC}_{2, k}=0\right)$, and in the second, only precipitation anomalies $\left(\mathrm{SSC}_{1, k}=0\right)$. This reveals the relative importance of fluctuations in temperature and precipitation. Apparently both quantities are important, although it can be seen that the large positive anomalies are related to large amounts of precipitation. In the bottom panel of Figure 3 the measured specific balance for Nigardsbreen is also shown for the period 1962-95. The correlation coefficient between reconstructed and measured balance is not very high $(r=0.65)$, most likely due to the relatively large distance between Bergen and Nigardsbreen.

When using dataset (ii) the result is somewhat better $(r=$ 0.76). Interestingly, the best result is obtained with dataset (iii), the ECMWFre-analyses (Fig. 4). For this dataset the correlation coefficient is 0.85 , but it should be noted that the period is shorter now (1979-93) because at the time of the analysis the ECMWF data did not cover a larger time-span.

\section{PERFORMANGE OF THE REDUGED MODEL}

As explained earlier, there are two basic assumptions about using Equation (6) to reconstruct glacier mass balance. The first is that the direct effect of monthly perturbations of temperature and precipitation can be described with a linear ex- pansion. This will work only when the perturbations are sufficiently small. Further analysis showed that, in practice, errors are acceptable $(<10 \%)$ if the temperature anomalies do not exceed $2 \mathrm{~K}$ and the precipitation anomalies do not exceed $40 \%$. Of course larger deviations occur occasionally, but, given other uncertainties, it is doubtful if the use of a higher-order expansion is worthwhile.

The second assumption involves the mutual interference of monthly perturbations. The effect of a temperature perturbation in June on the annual balance may depend to some extent on a precipitation perturbation in April, for instance.The best test for the reduced model is to compare it directly with the full mass-balance model, run in a timedependent mode for a longer period of time. We have done this for the Bergen dataset (i). The mass-balance model was started at the beginning of the year 1921 and run continuously with monthly temperature and precipitation as forcing. In principle, a perturbation in the beginning of the integration will affect the entire further evolution of the balance. Figure 5 shows how the result from this run compares with the output from the reduced model. Obviously the correspondence between the models is quite good. The root-mean-square difference is $0.22 \mathrm{mw}$.e., the correlation coefficient 0.97 .

We have repeated the comparison for 100 years of synthetic climate data. These were taken from a control run with a coupled ocean-atmosphere circulation model run at the Max-Planck-Institut für Meteorologie, Hamburg. The result was very similar and is therefore not shown. Again, the correlation coefficient was 0.97 .

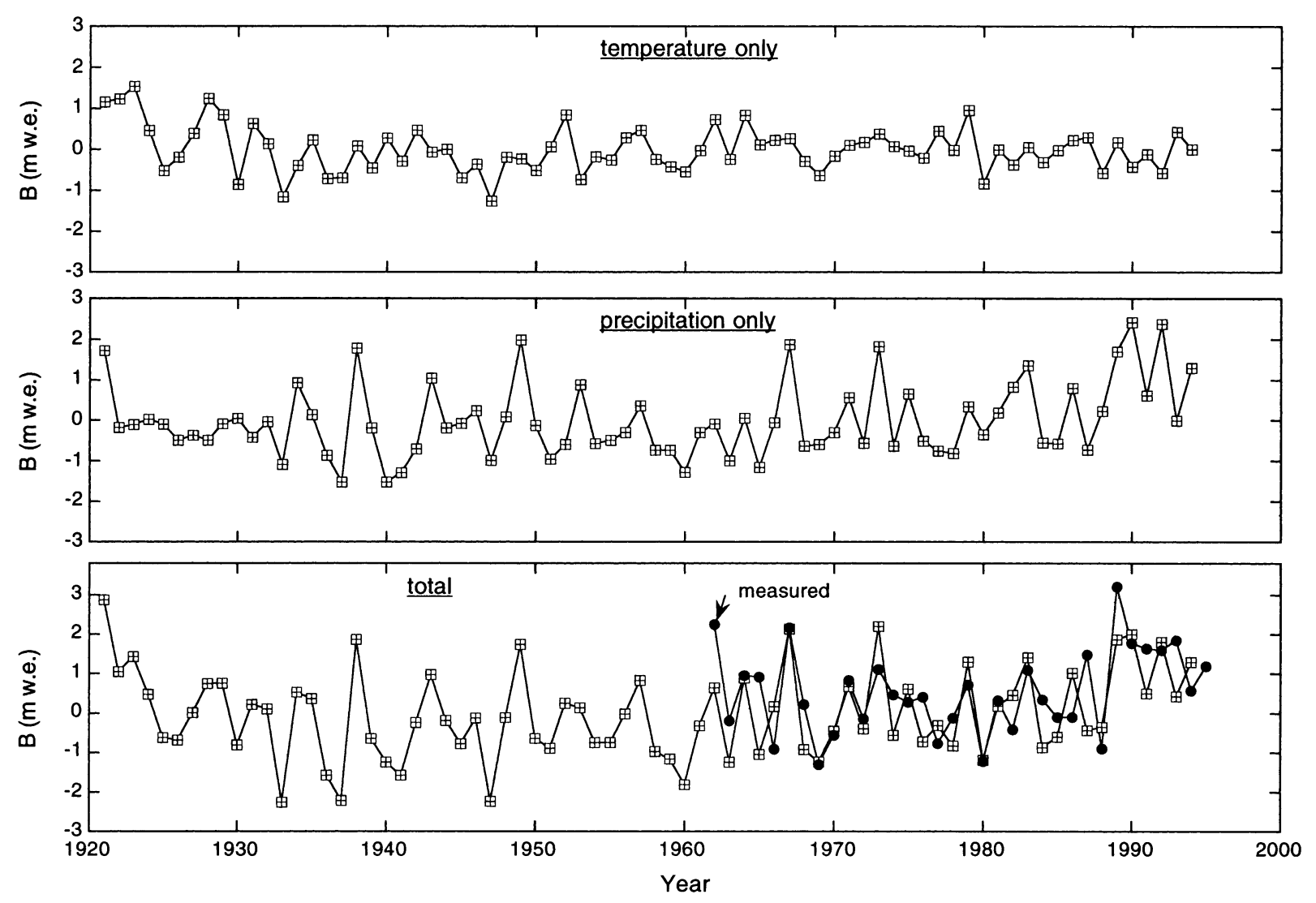

Fig. 3. Specific balance for Nigardsbreen calculated with the reduced model from monthly perturbations of temperature and precipitation as observed at Bergen. The calculation is for the present-day geometry. The upper panel shows the effect of temperature anomalies only, the middle panel the effect of precipitation anomalies only. In the bottom panel the reconstructed balance is compared with mass-balance measurements. Data from Müller (1977), Haeberli (1985), Haeberli and Müller (1988), Elvehøy and Haakensen (1992), Haeberli and Hoelzle (1993) and Haakensen (1995). 


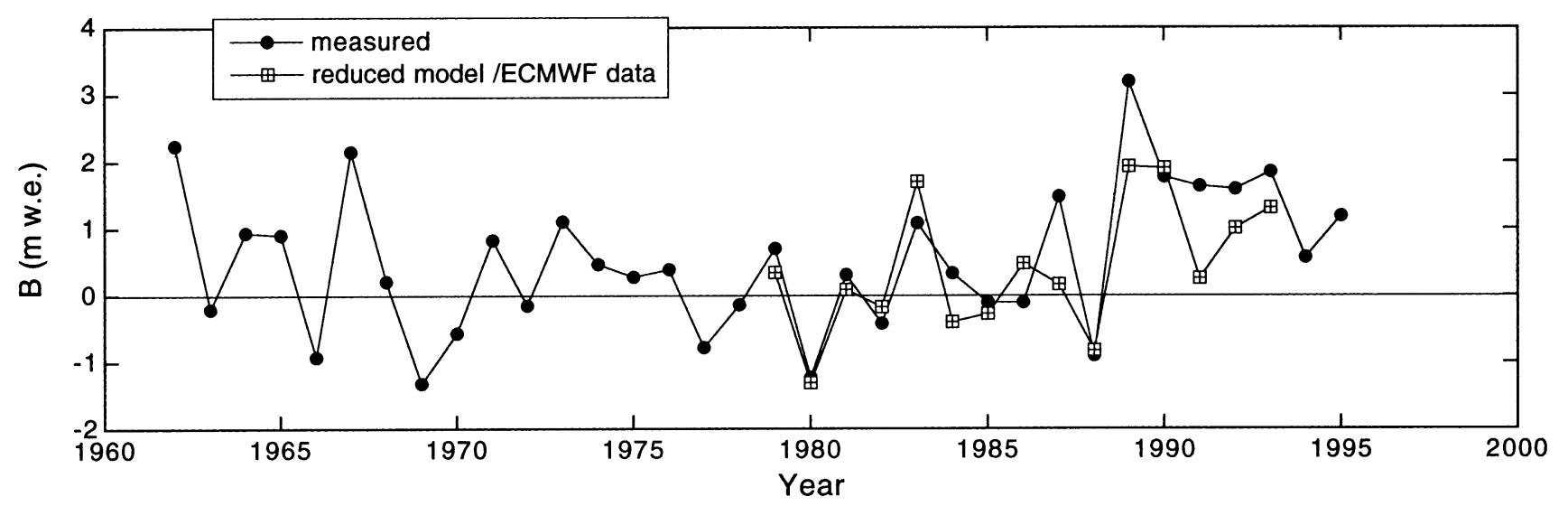

Fig. 4. A comparison between measured (dots) and reconstructed mean specific balance for Nigardsbreen. The reconstruction with the reduced model is done with data from ECMWFre-analyses.

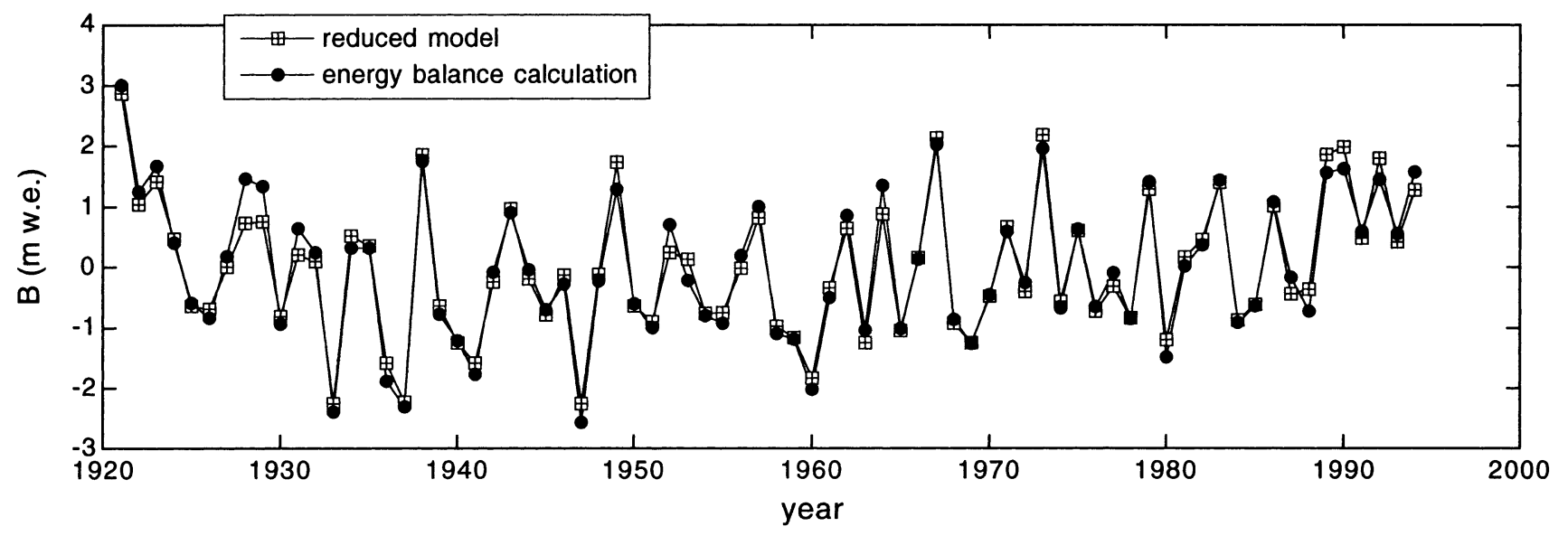

Fig. 5. Reconstructed specific balance for Nigardsbreen from the reduced model and a full energy-balance calculation. Input data are taken from the meteorological station at Bergen.

Another useful comparison is that between the SSC and the annual sensitivity, defined as the change in the mean specific balance for a perturbation in temperature or precipitation that is constant through the year. The annual sensitivity can be estimated from the SSC by summing up all monthly contributions. The result will not be equal to the outcome of the run of a mass-balance model with a constant perturbation through the year. In general, the estimate of the annual sensitivity from the SSC gives slightly smaller values. At least for the glaciers considered here, however, the differences are small $(<10 \%)$. This is additional evidence that mutual interference of monthly perturbations is not very significant.

\section{GONGLUDING REMARKS}

We think that the SSC is a well-defined and useful tool for characterizing the climatic setting of a glacier. It shows in a transparent way the difference in sensitivity between glaciers with large and small mass turnovers. It also shows the relative role of changes in temperature and precipitation. The accuracy of a calculated SSC depends on how well the massbalance model is designed and on the quality of the input data. Even though there are significant uncertainties in these, we believe that the gross characteristics shown in Figure 1 are real. The finding that summer temperature is more important for drier glaciers also appears to be a robust result.

Using the SSC to (re)construct a mass-balance series is straightforward. We found the difference between the re- duced model and the full energy-balance calculation to be small, and irrelevant in view of other uncertainties.

We did not discuss how balance profiles might change. In the results from the mass-balance model there is a tendency towards larger balance gradients for higher temperatures. However, the effect is significant only for the driest glaciers in the sample (White Glacier and Devon Ice Cap).

\section{ACKNOWLEDGEMENT}

This work has been partly supported by the Framework IV Research Programme of the European Union (contract ENV4-CT97-0490).

\section{REFERENCES}

Dyurgerov, M. B. and M.F. Meier. 1997. Year-to-year fluctuations of global mass balance of small glaciers and their contribution to sea-level changes. Arct. Alp. Res., 29(4), 392-402.

Elvehøy, H. and N. Haakensen. 1992. Glasiologiske undersøkelser i Norge 1990 og 1991. NVE, Norges Vassdrags-og Energiverk. Hydrologisk Avdeling. Publikasjon 3.

Greuell, W. 1992. Hintereisferner, Austria: mass-balance reconstruction and numerical modelling of the historical length variations. F. Glaciol., 38(129), 233-244.

Greuell , W. H., W. H. Knap and P. C. Smeets. 1997. Elevational changes in meteorological variables along a midlatitude glacier during summer. $\mathcal{F}$. Geophys. Res., 102 (D22), 25, 941-25, 954.

Günther, R. and D. Widlewski. 1986. Die Korrelation verschiedener Klimaelemente mit dem Massenhaushalt alpiner und skandinavischer Gletscher. z. Gletscherkd. Glazialgeol., 22(2), 125-147. 
Haakensen, N., ed. 1995. Glasiologiske undersøkelser i Norge 1992 og 1993. NVE, Norges Vassdrags-og Energiverk. Hydrologisk Avdeling. Publikasjon 08.

Haeberli, W., comp. 1985. Fluctuations of glaciers 1975-1980 ( Vol. IV). Paris, International Commission on Snow and Ice of the International Association of Hydrological Sciences/UNESCO.

Haeberli, W. and M. Hoelzle, comps. 1993. Fluctuations of glaciers, 19851990 ( Vol.VI). Wallingford, Oxon, IA Press; Nairobi, UNEP; Paris, UNESCO.

Haeberli, W. and P. Müller, comps. 1988. Fluctuations of glaciers 1980-1985 ( Vol. $V$ ). Wallingford, Oxon, IAHS Press; Nairobi, UNEP; Paris, UNESCO.

Hoinkes, H. and R. Steinacker. 1975. Zur Parametrisierung der Beziehung Klima-Gletscher. Riv. Ital. Geofis. Sci. Affini, 1, 97-104.

Letréguilly, A. 1984. Bilans de masse des glaciers alpins: méthode de mesure et répartition spatio-temporelle. (Thèse de 3ème cycle, Laboratoire de Glaciologie du CNRS et Université Joseph Fourier, Grenoble.) (Publ. 439.)

Lliboutry, L. 1974. Multivariate statistical analysis of glacier annual balances. f. Glaciol., 13(69), 371-392.

Meier, M. F. 1984. Contribution of small glaciers to global sea level. Science, 226 (4681), 1418-1421.
Müller, F., comp. 1977. Fluctuations of glaciers 1970-1975 (Vol. III). Paris, International Commission on Snow and Ice of the International Association of Hydrological Sciences/UNESCO.

Nye, J.F. 1965. A numerical method of inferring the budget history of a glacier from its advance and retreat. F. Glaciol., 5(41), 589-607.

Oerlemans, J. 1992. Climate sensitivity of glaciers in southern Norway: application of an energy-balance model to Nigardsbreen, Hellstugubreen and Alfotbreen. 7. Glaciol., 38(129), 223-232.

Oerlemans, J. 1997. Climate sensitivity of Franz Josef Glacier, New Zealand, as revealed by numerical modeling. Arct. Alp. Res., 29(2), 233-239.

Oerlemans, J. and J. P. F. Fortuin. 1992. Sensitivity of glaciers and small ice caps to greenhouse warming. Science, 258 (5079), 115-117.

Smith, I.N. and W.F. Budd. 1981. The derivation of past climate changes from observed changes of glaciers. International Association of Hydrological Sciences Publication 131 (Symposium at Canberra 1979 - Sea Level, Ice and Climatic Change), 31-52.

Zuo, Z. andJ. Oerlemans. 1997. Contribution of glacier melt to sea-level rise since AD 1865: a regionally differentiated calculation. Climate Dyn., 13, $835-845$.

MS received 22 June 1998 and accepted in revised form 23 June 1999 